\title{
XXXV. On the determination of high temperatures with the meldometer
}

\section{William Ramsay Ph.D. F.R.S. \& N. Eumorfopoulos B.Sc.}

To cite this article: William Ramsay Ph.D. F.R.S. \& N. Eumorfopoulos B.Sc. (1896) XXXV. On the determination of high temperatures with the meldometer , Philosophical Magazine Series 5, 41:251, 360-367, DOI: $10.1080 / 14786449608620850$

To link to this article: http://dx.doi.org/10.1080/14786449608620850

Published online: 08 May 2009.

Submit your article to this journal $₫$

Џ Article views: 2

Q View related articles $\square$ 
the power was varied by varying the potential-difference of the carbons, and the alternating-current are lamp used was one which effected this variation automatically, even although the power expended in the arc was varied from 200 to 600 watts. In order to complete the comparison of the continuous and alternating-current arcs, it will be necessary to compare the behaviour as regards illuminating-power of alternatingcurrent arcs, taking the same mean power but formed with larger currents and less carbon potential-differences; that is to say, comparing alternating ares of equal power-absorption, but taking very different currents and therefore having different lengths. We hope to extend this investigation to cover these additional questions at some future time.

The above observations have necessitated an enormous number of photometric and electrical measurements, and we have in the above work been very efficiently aided by Messrs. L. Birks, W. H. Grimsdale, A. M. Hanbury, E. N. Griffiths, and others, to whom our thanks are due.

XXXV. On the Determination of High Temperatures with the Meldometer. By William Ramsax, Ph.D., F.R.S., Professor of Chemistry, University College, London, and N. Eumorfopoulos, B.Sc., Demonstrator of Physics, University College, London*.

THE meldometer, an instrument devised by Dr. Joly, has 1 been sufficiently described by him (Proc. Roy. Irish Acad. 3rd series, ii. p. 38, or (hem. News, vol. lxv.), and we need therefore only give a very brief account of it here. The essential part of the instrument is a length (about 10 centim.) of thin uniform platinum ribbon, about 1 millim. wide. This is heated by a current of adjustable strength, and the increase in length of the ribbon is measured by a delicate micrometerscrew, the ribbon being kept gently stretched by a small spring. The temperature of the ribbon is, of course, lower where the two forceps hold it; but if it is suitably cut at each end nearly to a point, a length of, say, 6 centim. in the middle may be made of a very uniform temperature, as can be proved experimentally by taking the reading of the meltingpoint of the same substance at different points along the ribbon.

An infinitesimal quantity (scarcely visible with the naked eye) of the substance to be melted is placed on the ribbon and viewed with a low-power microscope. The small quantity of

* Communicated by the Physical Society: reed February 14, 1896. 
Determination of Temperatures with the Meldometer. 361

the substance required enables it to be purified very completely. The current is then put on and increased rapidly until the substance melts, and thus an approximate reading is obtained. This is repeated more cautiously, to obtain an exact reading. Several readings can be taken by remelting the same, and also by using fresh substance, the latter method being usually adopted.

To translate the readings into temperatures, it is necessary to standardize the instrument by taking the readings with substances of known melting-points. Of these, unfortunately, there are none known with certainty beyond about $350^{\circ}$ ( ). One reading is obtained by taking the temperature of the air, another is the melting-point of potassium nitrate $\left(339^{\circ}\right)$, and for a third one the melting-point of potassium sulphate $\left(1052^{\circ}\right)$ was adopted, for reasons that will appear. The melting-point of silver is irregular, apparently because of absorption of oxygen, and consequent spitting. Gold can be used, and also palladium. As, however, the expansion of the ribbon is almost a linear function of its temperature, and as the observations hitherto taken did not extend beyond about $1050^{\circ}$, it was considered unnecessary to take readings with palladium, the general character of the expansion of the ribbon being already known from Dr. Joly's observations. 'The question next arises, what is the melting-point of gold? There have been two or three determinations of value, which unfortunately differ from one another.

M. Violle (C.R. 1879) determined it by a calorimetric method, and obtains as a result $1045^{\circ}$ (on the air-thermometer).

Messr's. Holborn and Wien (Wied. Ann. xlvii. and lvi., 1892 and 1895 ), who give $1072^{\circ}$, compared a thermo-element with an air-thermometer, and then used the former for determining the melting-points of silver, gold, and copper. This was done by inserting in a porcelain crucible the thermoelement, and also two platinum wires connected by a wire of the substance whose melting-point was to be taken. The platinum wires formed part of a circuit containing a battery and a galvanometer. When the wire melted, the circuit was broken, and the temperature read at the same moment with the thermo-element. The melting of the substance must in general lag a little behind the thermo-element; and as no mention is made of the rate at which the temperature was raised, it is difficult to know how far the results can be trusted. They obtain, however, very concordant readings.

Besides these, there are two determinations with the platinum pyrometer : one by Professor Callenáar (Phil. Mag. Feb. 


\section{Prof. W. Ramsay and N. Eumorfopoulos on the}

1892), and the other by Messrs. Heycock and Neville (J. C. S. Trans. 1895, p. 160). By a somewhat violent extrapolation* from a formula which, as far as we know, has been compared with the air-thermometer only to about $625^{\circ}$, they obtain :-

$\begin{array}{cccc} & & \text { Callendar. } & \text { Heycock and } \\ \text { Neville. }\end{array}$

Callendar then, taking the melting-point of silver as $945^{\circ}$, makes the melting-point of gold $1037^{\circ}$. Now Violle's determination for silver is $954^{\circ}$, which, using Callendar's formula, would give for gold $1049^{\circ}$. Holborn and Wien's value for silver is $968^{\circ}$. In view of the variance between the numbers, it was determined to take Violle's value, though the correct value may be a few degrees higher (compare Le Chatelier, $C . R$. exxi. p. 323,1895 ). In any case, allowance can easily be made, when further researches have determined the true melting-point.

The gold used by us was a very pure specimen obtained from Messrs. Johnson and Matthey. The salts used, with the exception of some of the iodides, were pure specimens, prepared specially by ourselves. In a few cases the salts so prepared were recrystallized, and melting-points were taken both of the recrystallized salt and also that obtained from the mother liquor. No difference could be detected, and bence no further mention is made of these determinations.

Gold on melting alloys with the platinam, and hence must destroy to a certain extent the uniformity of the ribbon. A

* In Holborn and Wien's last paper (loc. cit.) the resistance of pure platinum is determined at different temperatures with their thermoelement, and their results cannot be expressed quite satistactorily (" nur ungenitgend") by means of (allendar's formula. The resistance of two of their pure platinum wires began to differ beyond about $900^{\circ}$, while agreeing below this temperature. They therefore consider this property unsuited to extrapolation.

+ In a recent paper (J. C. S. Trans. 1895, p. 1025) Heycuck and Neville state that "Callendar did not rigidly follow the method of calibration, which was afterwards developed by Griffiths and himself, and which we have always adhered to. That method requires that the resistance of the pyrometer should be determined at three standard temperatures," viz., at $0^{\circ}, 100^{\circ}$, and the boiling-point of sulphur, $444^{\circ} \cdot 5$. And lower down they say, "If" Callendar had standardized his thermoneter on the boiling-point of sulphur....; " hence they infer that Callendar did not use the boiling-point of sulphur for this determination. But the determination of this boiling-point is given in Phil. Trans. 1891, i.e., it was published before the paper referred to, and the latter is also later than another paper (Plil. Mag. July 1891, p. 109), in which the boilingpoint of sulphur is directly referred to. We do not quite see how to reconcile the various statements. 
Determination of Temperatures with the Meldometer. 363

remedy for this is to dust the ribbon lightly with finely powdered talc. This, however, is not very satisfactory, and interferes somewhat with the observations; but with care, fairly good results can be obtained, as the following numbers show:-

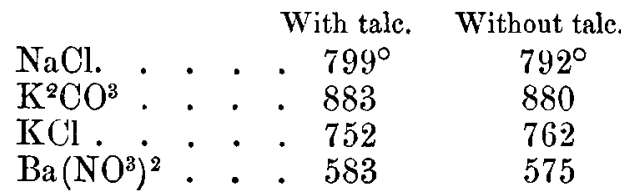

It was then found that the melting-point of potassium sulphate is very little different from that of gold, viz., 7 degrees higher or $1052^{\circ}$; and this salt was afterwards used instead of the gold ; thus there is no need to use talc.

Some melting-points are sharply marked, others are not. In these cases the lowest point was taken at which spreading over the ribbon could be detected.

For purposes of comparison determinations by other observers are given; some determined the melting-points (e.g., Carnelley, and Meyer, Riddle and Lamb), others the freezingpoints (Carnelley, Le Chatelier, Heycock and Neville, and McCrae). The data are taken from the following references:-

Carnelley (calorimetric method): J. C. S. Trans. 1876, p. $489 ; 1877$, p. $365 ; 1878$, p. 273.

Le Chatelier (thermo-electric method, assuming meltingpoint of gold as $1045^{\circ}$ ): Bull. Soc. Chim. t. xlvii. p. 301; C. R. t. exviii. pp. 350,711 , and 802 .

V. Meyer, Riddle and Lamb: Ber. xxvii. (1894) p. 3129. - In this method the salt has been previousiy fused in a platinum tube with a wire down its centre, and to this wire is attached a weight passing over a pulley. When the salt melts, it is pulled out by the weight, and the temperature is determined at the same moment by an air-thermometer.

J. MeCrae (Wied. Ann. lv. p. 95), relying on Holborn and Wien's results, standardized his thermo-element with boiling diphenylamine $\left(304^{\circ}\right)$ and boiling sulphur $\left(444^{\circ} \cdot 5\right)$. For his thermo-element he used platinum against an alloy of platinum rhodium, and also against an alloy of platinum and iridium. The numbers in brackets given below refer to the latter, and the others to the former. It will be noticed that they do not agree perfectly. This may, of course, be due to his metals not being of the same purity as those of Holborn and Wien. The latter also from their observations find that the iridium alloy is not as well suited as the rhodium alloy. 
364 Prof. W. Ramsay and N. Eumorfopoulos on the

Salts of Lithium.

The lithium carbonate bought as pure gave a conspicuous sodium coloration to the Bunsen flame. It was purified by suecessive precipitation and washing, until it gave a brilliant carmine coloration to a Bunsen flame, free from yellow fringe, showing an absence of sodium. The meltingpoints are not very well marked as a rule.

\begin{tabular}{|c|c|c|c|c|}
\hline \multirow[b]{2}{*}{$\mathrm{Li}^{2} \mathrm{SO}^{4}$} & \multicolumn{2}{|c|}{$\begin{array}{c}\text { Ramsay \& } \\
\text { Fumorfopoulos. }\end{array}$} & \multirow{2}{*}{$\begin{array}{l}\text { Carnelley. } \\
818\end{array}$} & \multirow{2}{*}{$\begin{array}{c}\text { Le Chatelier. } \\
830\end{array}$} \\
\hline & ............ & 853 & & \\
\hline $\mathrm{Li}^{2} \mathrm{CO}^{3}$ & ............. & 618 & 695 & 710 \\
\hline LiOl... & …........ & 491 & 598 & \\
\hline $\mathrm{LiBr}$ & …......... & 442 & 547 & \\
\hline LiI $\ldots$ & ........ belo & 330 & 446 & \\
\hline
\end{tabular}

It will be noticed that there is here no agreement between the results of different observers. Our results are as a rule about 100 degrees lower than Carnelley's, except that of the sulphate. Our resistances did not allow us to take the melting-point of lithium iodide, as we had not arranged for temperatures below $330^{\circ}$, but its melting-point is below that of potassium nitrate $\left(339^{\circ}\right)$. Lithium iodide is very hygroscopic, so that on placing it on the ribbon it quickly liquefies; then on putting on the current, it becomes solid and then liquid again at the temperature given above, i. e., it has melted, and remains so indefinitely.

\section{Salts of Sodium.}

The salts of sodinm and potassium were prepared from the bicarbonate, precipitated by carbonic acid from a solution of the pure carbonate. The melting-points are well marked, though all are not equally so, e.g., the iodides.

\begin{tabular}{|c|c|c|c|c|c|c|}
\hline \multicolumn{2}{|c|}{$\begin{array}{c}\text { Ramsay \& } \\
\text { Eumorfopoulos. }\end{array}$} & Carnelley. & $\begin{array}{l}\text { Le Cha- } \\
\text { telier. }\end{array}$ & \multirow{2}{*}{$\begin{array}{c}\text { Moyer, } \\
\text { Riddle } \\
\text { \& Lamb. } \\
863\end{array}$} & \multirow{2}{*}{$\begin{array}{c}\text { Heycock \& } \\
\text { Neville. } \\
883\end{array}$} & \multirow{2}{*}{$\begin{array}{c}\text { MeCrae. } \\
883\end{array}$} \\
\hline $\mathrm{Na}^{2} \mathrm{SO}^{4} \ldots$ & 884 & 861 & 860 & & & \\
\hline $\mathrm{Na}^{2} \mathrm{CO}^{3} \ldots$ & 851 & 814 & 820 & 849 & 852 & $861(854)$ \\
\hline $\mathrm{NaCl} \ldots . .$. & 792 & 772 & 778 & 815 & $\ldots$ & 813 \\
\hline NaBr...... & 733 & 708 & $\cdots$ & 758 & $\ldots$ & 761 \\
\hline $\mathrm{NaI}$ & 603 & 628 & $\ldots$ & 661 & $\cdots$ & $695(668)$ \\
\hline
\end{tabular}

The agreement between Messrs. Heycock and Neville's results and our own is only apparent, as they find $1062^{\circ}$ as the melting-point of gold, while we assume $1045^{\circ}$. The fact that they are determining freezing- and not melting-points may introduce some difference. 
Determination of Temperatures with the Meldometer. 365

\begin{tabular}{|c|c|c|c|c|c|c|}
\hline \multicolumn{7}{|c|}{ Salts of Potassium. } \\
\hline & $\begin{array}{c}\text { Ramsay \& } \\
\text { Eumorfopoulos. }\end{array}$ & Carnolley. & $\begin{array}{l}\text { Le Oha- } \\
\text { telier. }\end{array}$ & $\begin{array}{l}\text { Meyer, } \\
\text { Riddle } \\
\text { \& Lamb. }\end{array}$ & $\begin{array}{l}\text { Heycock \& } \\
\text { Neville. }\end{array}$ & McOrao. \\
\hline $\mathrm{K}^{2} \mathrm{SO}^{4}$. & .. 1052 & $\ldots$ & 1045 & 1078 & 1066.5 & $1059(1166)$ \\
\hline $\mathrm{K}^{2} \mathrm{CO}^{9}$. & 880 & 834 & 860 & 879 & $\ldots$ & $893(885)$ \\
\hline $\mathbf{K C l} \ldots . .$. & 762 & 734 & 740 & 800 & $\ldots$ & 800 \\
\hline $\mathbf{K B r}$ & 733 & 699 & $\cdots$ & 722 & $\ldots$ & $746(709)$ \\
\hline KI ..... & 614 & 634 & 640 & 685 & $\ldots$ & $723(677)$ \\
\hline
\end{tabular}

M. Le Chatelier gives an earlier value $1015^{\circ}$ for potassium sulphate, and also $885^{\circ}$ for potassium carbonate. Our value for potassium sulphate is 7 degrees above that of gold. Messrs. Heycock and Neville's is 4.5 above their value for gold, but they mention that there may be an error of 2 degrees, due to the alkalinity of their potassium sulphate.

\section{Salts of Calcium, Strontium, and Barium.}

The salts of calcium, strontium, and barium were prepared from their carbonates precipitated from the purified nitrates. Their melting-points are not well marked, especially those of calcium; and here again the iodides are less well marked than the chlorides.

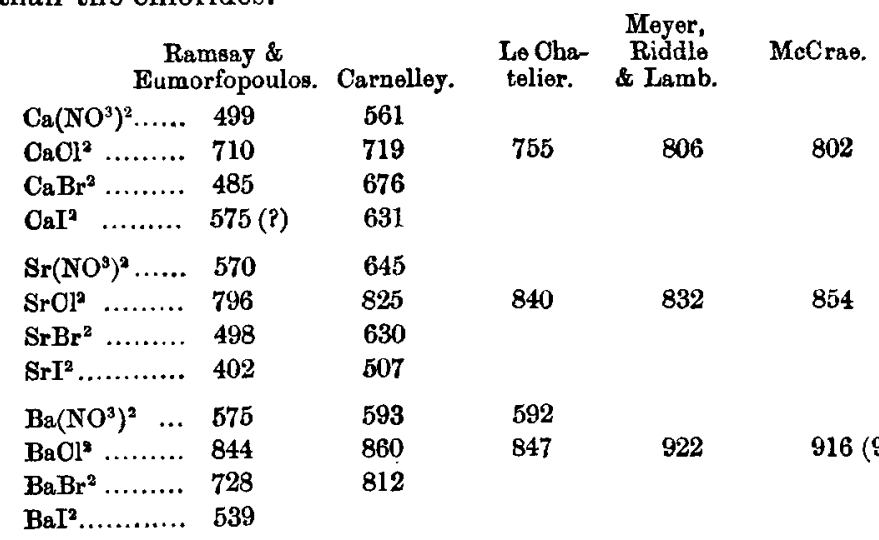

Calcium chloride is very difficult to observe, as it slowly softens. We found it practically impossible to take the melting-point of calcium iodide, as it is exceedingly hygroscopic, and, on heating, it is almost immediately oxidized. We do not think it can be above the value given, though it may be below it.

Salts of Silver and Lead.

These were prepared by precipitation. Their meltingpoints are well marked.

Phil. Mag S. 5. Vol, 41. No. 251. April 1896. $2 \mathrm{C}$ 
366 Determination of Temperatures with the Meldometer.

\begin{tabular}{|c|c|c|}
\hline & $\begin{array}{c}\text { Ramsay \& } \\
\text { Eumorfopoulos. }\end{array}$ & Carnelley. \\
\hline $\mathrm{Ag}^{2} \mathrm{SO}^{4}$ & $\ldots 67 b^{\circ}$ & 654 \\
\hline $\mathrm{AgCl} .$. & $\ldots \quad 460$ & 451 \\
\hline $\mathrm{AgBr}$ & $\ldots \ldots \quad 426$ & 427 \\
\hline AgI .... & $\ldots \ldots . \quad 556$ & 527 \\
\hline $\mathrm{PbSO}^{4}$. & $\begin{array}{ll}\ldots . .937\end{array}$ & \\
\hline $\mathrm{PbCl}^{2}$ & 447 & 498 \\
\hline $\mathrm{PbBr}^{2}$ & 363 & 499 \\
\hline $\mathrm{PbI}^{2} \ldots$ & $\ldots \ldots . \quad 373$ & 383 \\
\hline
\end{tabular}

A curve is appended with the melting-points of the salts of potassium marked on it. In drawing this curve there must

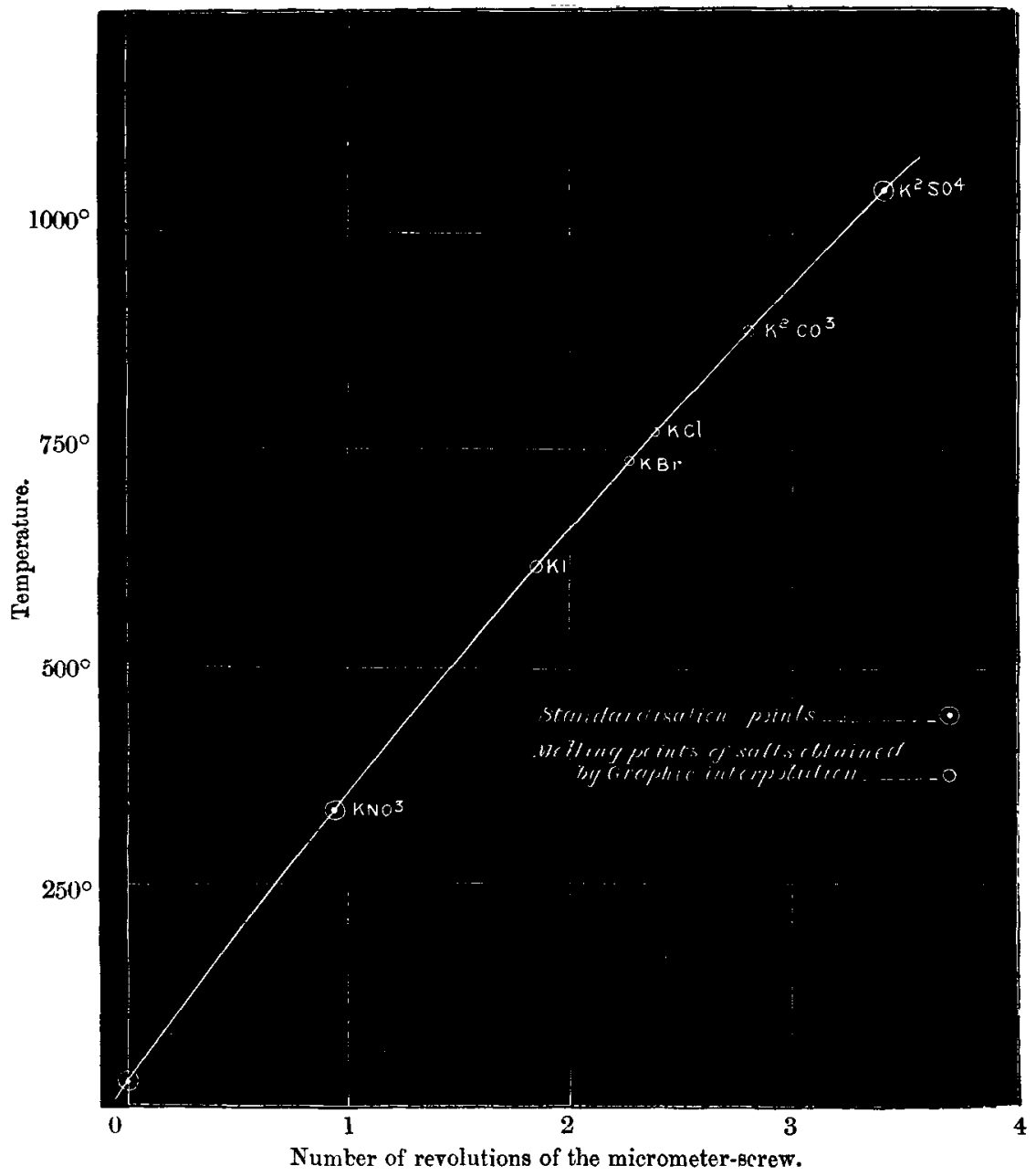


of necessity be a small uncertainty, as there is no datum-point between $339^{\circ}$ and $1052^{\circ}$; but this cannot amount to more than a very few degrees.

In conclusion, we may point out that plotting our meldometer-readings against other observers' melting-points does not give a smooth curve.

University College, London.

XXXVI. The Magnetic Field of any Cylindrical Coll. By W. H. Everett, B.A.*

A PPLYING Ampère's formula for the magnetic force $A$ at any point due to an element of current, the force perpendicular to any plane circuit, carrying a current $i$, is found to be, at any point $P$,

$$
\mathrm{Z}^{\prime}=i \int \frac{r d^{2} \theta}{\left(r^{2}+h^{2}\right)^{\frac{3}{2}}}
$$

$h$ being the distance of $\mathrm{P}$ from the plane of the circuit, and $r, \theta$ the polar co-ordinates of any point of the circuit referred to the projection of $\mathrm{P}$ as origin.

The longitudinal force at any point due to a current in a cylindrical coil, or solenoid, is given by a second integration. It is the sum or difference of two terms, each of the form

$$
\mathrm{Z}=\operatorname{inh} \int \frac{d \theta}{\sqrt{r^{2}+h^{2}}}
$$

where $h$ denotes the distance of the point from an end plane of the solenoid, and $n$ the number of turns per unit length of $h$. The depth of the coil, normal to the cylindrical surface, is assumed to be inconsiderable. The limits of integration are 0 and $2 \pi$ for any point whose projection, taken parallel to the axis, falls within the solenoid.

Similarly, the transverse force at any point, due to a solenoid, is found to be

$$
\mathrm{R}=\operatorname{in} \Sigma\left(\frac{1}{\sqrt{r^{2}+h_{1}^{2}}}-\frac{1}{\sqrt{r^{2}+h_{2}^{2}}}\right) d s,
$$

the summation being vectorial.

The latter two formulæ can be readily applied, for approximate calculation, to a cylindrical coil of any cross-section,

* Communicated by the Physical Society, being abstract of paper read November $8,1895$. 